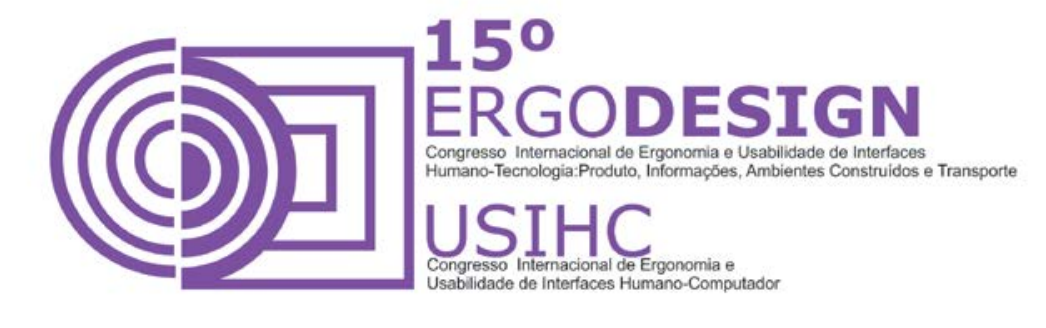

\title{
FERRAMENTAS, MÉTODOS E PROTOCOLOS DE ANÁLISE ERGONÔMICA DO TRABALHO
}

\section{ERGONOMICS ANALYZIS TOOLS, METHODS AND PROTOCOLS AT WORK}

\author{
STRABELI, Giovana I. (1); \\ NEVES, Érica P. (2). \\ (1) UFSCar ${ }^{1}$, Mestranda \\ e-mail: ginnocenti@hotmail.com \\ (2) UNESP ${ }^{2}$, Mestranda \\ e-mail:ericapneves@gmail.com
}

\begin{abstract}
RESUMO
O trabalho, fundamental à vida humana, aliado à evolução da sociedade e à competitividade, resultaram na constante diligência em equalizar ambientes profissionais produtivos e seres humanos em condições de segurança e saúde. Os conceitos ergonômicos objetivam evitar riscos acidentais, operacionais e minimizar a fadiga. Alicerçado nessa demanda, este estudo evidencia as ferramentas, métodos e protocolos de análise ergonômica como a Análise Ergonômica do Trabalho - AET, a Ergonomics Workplace Analysis - EWA - a NIOSH, OWAS e RULA. Somente o conhecimento profundo do tema e a preocupação com a saúde e a segurança do trabalhador proporcionará uma força de trabalho eficiente e evoluída.

Palavras - chave: Ferramentas, Análise Ergonômica, Trabalho.
\end{abstract}

\begin{abstract}
The work, essential to human life, combined to the progress of society and the competitiveness resulted in a constant diligence to equalize productive professionals environments and human in health and safety conditions. The ergonomic concepts aim to avoid accidental, operational risks and minimize fatigue. Founded in this demand, this study highlights the tools, methods and protocols ergonomic analysis such as Ergonomic Work Analysis - AET, the Workplace Ergonomics Analysis - EWA - NIOSH, OWAS and RULA. Only the deep knowledge about this subject and the concern for worker health and safety will provide an efficient and evolved workforce.
\end{abstract}

\footnotetext{
${ }^{1}$ Rod. Washington Luis, km 235 - São Carlos - SP - Brasil - CEP. 13656-95.

${ }^{2}$ Av. Eng. Luiz Edmundo Carrijo Coube, no 14-01 - Bauru - SP - Brasil - CEP.17033-360.
} 


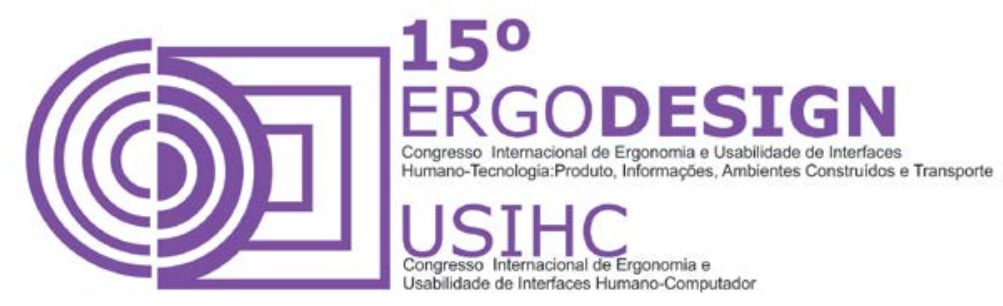

Keywords: Tools, Ergonomic Analysis, Work.

\section{INTRODUÇÃO}

O universo do trabalho sofreu e vem sofrendo constantes processos de reestruturação produtiva e organizacional decorrentes do desenvolvimento da sociedade e a configuração de novos paradigmas como a globalização, a alta produtividade, a competitividade e a mecanização fatores que impelem as organizações à busca por transformações estratégicas tanto gerenciais quanto operacionais.

Atualmente, parte dessa reestruturação parte do pressuposto de que o intelecto sobrepõe-se à força e, Toffler (1980) caracteriza essa nova estrutura como a "sociedade da informação". Essa metamorfose deu origem à era do conhecimento, que impulsiona uma reprogramação de valores, em que os recursos humanos e a sua força motriz são essenciais e prioridade.

Desta forma para desenvolver as atividades de trabalho, o homem precisa estruturar o espaço sensório-motor, conhecer o barulho da máquina, ter à mão os instrumentos de trabalho, contar com os membros da equipe e as condições do trabalho constituindo-se então como condições da atividade pessoal, e que essa relação pessoal da atividade no resultado pretendido está mediatizada por condições espaciais, temporais, técnicas, organizacionais, relacionais, nas quais se desenvolve a atividade (GUERIN et al, 2001).

Portanto, o subsídio para o desenvolvimento de uma atividade de trabalho é a condição de trabalho, definida por Leplat e Cuny (1998) como o conjunto de fatores determinantes da conduta do trabalhador. Estes fatores são compostos pelo roteiro e formalização das tarefas a serem executadas e/ou pelas características pessoais do colaborador, sejam físicas, intelectuais ou de personalidade.

Para Guerin et al (1991), Codo; Gazzotti (1999), o trabalho constitui-se como um núcleo ao redor do qual o indivíduo se constrói e organiza sua vida pessoal. Articulado socialmente como papel compõe o marco de referência para o estabelecimento de aspirações, estilo de vida, percepção da própria identidade e daquela das pessoas que através dele se inter-relacionam.

Conforme a Previdência Social (2010), as estatísticas de acidentes e doenças nos ambientes laborais retratam a necessidade da intensificação no conhecimento da ergonomia como fator de extrema importância para as organizações. A ergonomia é defendida como o "estudo do trabalho a não ser enquanto abordagens ou explicações mais ou menos superficiais, que devem ser mais cedo ou mais tarde aglutinadas num todo mais global e coerente" (MENDES, 2003, p. 1778).

Isto posto, este estudo se propõe a levantar as ferramentas, métodos e protocolos de análise ergonômica do trabalho mais recorrentes dentre as organizações, almejando ampliar a base teórica acerca desses além de salientar sua relevância uma vez que segundo Santos et al (1997, p.268) "o desempenho do ser humano na execução de suas atividades de trabalho está relacionado às condições de trabalho que the são impostas. Em particular, às condições 


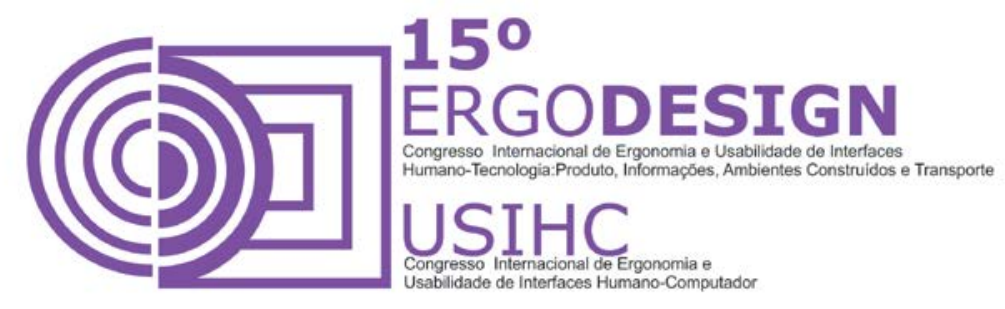

organizacionais e às condições ambientais e técnicas, que determinam respectivamente sua motivação e satisfação no trabalho".

\section{REFERENCIAL TEÓRICO}

As ferramentas, métodos e protocolos de análise ergonômica avaliam e apontam as condições em que o trabalhador está submetido ao realizar determinada atividade. Com esse diagnóstico é possível identificar as situações que mais prejudicam a saúde do colaborador, desde o levantamento de carga excessiva, às posturas inadequadas e aos movimentos repetitivos.

Segundo Abrahão; Pinho (1999), a execução do trabalho e a base da análise ergonômica podem ser compreendidas sob diferentes dimensões:

- O que o trabalhador faz: são as ações e decisões que o trabalhador toma para atingir os objetivos;

- a forma como o trabalhador usa de si para atingir os objetivos, adaptações dos atores ao trabalho;

- estratégias operatórias adotadas pelo trabalhador para atingir os objetivos.

$\mathrm{Na}$ visão de Shida; Bento (2012), alguns métodos utilizados para análise das condições de trabalho, tais como a AET e o EWA também são essenciais na avaliação e organização do trabalho, bem como do ambiente ocupacional, a fim de torná-los adaptáveis às necessidades, habilidades e limitações das pessoas.

Além das duas ferramentas citadas anteriormente, a NR-17 aponta o método NIOSH para a análise de trabalhos com carga estática e, portanto, ela será apresentada também nesse capítulo. A ferramenta OWAS será estudada a fim de elucidar a análise de postura. Por fim, será abordado o protocolo RULA indicado para avaliações detalhadas dos membros superiores e suas movimentações.

\section{AET - Análise Ergonômica do Trabalho}

O aperfeiçoamento teórico e o aprofundamento dos métodos da ergonomia focada na análise da atividade se deram a partir de 1955, após a publicação do livro de Faverge e Ombredane sobre a análise do trabalho, o que proporcionou a aplicação e a transformação das condições de trabalho mais elaboradas (GÜÉRIN et al., 2001; MONTMOLLIN, 2007; LAVILLE, 2007).

Segundo Shida; Bento (2012), a AET é "oriunda da escola franco-belga de ergonomia e que, desde os seus primórdios, tem possibilitado a compreensão e a transformação de inúmeras situações de trabalho.". O principal objetivos dessa ferramenta é aplicar os conhecimentos da ergonomia a fim de analisar, diagnosticar e corrigir determinada situação de trabalho. Esta técnica foi desenvolvida por pesquisadores franceses e pode ser considerada como um exemplo da ergonomia corretiva, ou ergonomia de correção (IIDA, 2005).

A AET é direcionada à análise da atividade e embasada na averiguação das situações de trabalho, ademais ela promove a adaptação do trabalho ao homem e centraliza sua atenção na transformação dos agentes determinantes de dado cenário de trabalho. De acordo com Guérin (2001), a priori a ação ergonômica é transformar o trabalho. Sendo assim, com a análise 


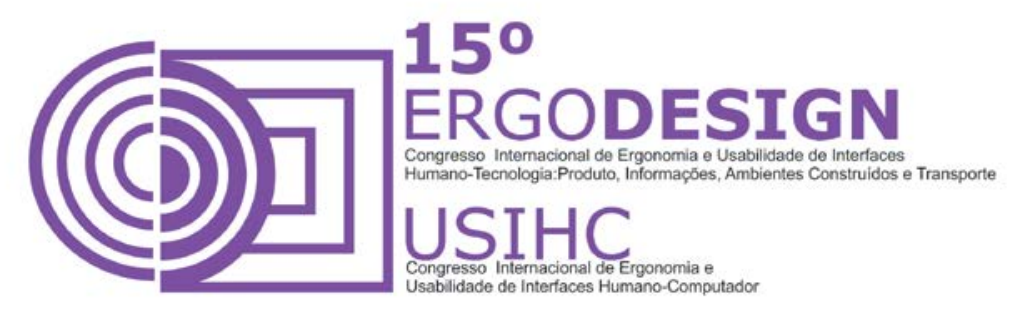

ergonômica do trabalho pode-se verificar as condições reais do ambiente de trabalho, as funções desempenhadas e as condições reais da tarefa executadas pelos trabalhadores (IIDA, 2005).

Shida; Bento (2012) denotam que, para o ergonomista, essa transformação deve ser realizada de forma a contribuir para:

- A concepção de situações de trabalho que não alterem a saúde dos operadores e nas quais estes possam exercer suas competências, ao mesmo tempo num plano individual e coletivo;

- encontrar possibilidades de valorização de suas capacidades e alcançar os objetivos econômicos determinados pela empresa, em função dos investimentos realizados.

A análise ergonômica faz com que se tenha uma compreensão de tudo que aconteceu no trabalho, mostrando, principalmente, o desempenho de produção do funcionário e lida (2005) sugere que a AET seja elaborada a partir de cinco etapas e o processo metodológico é apresentado na Figura 2:

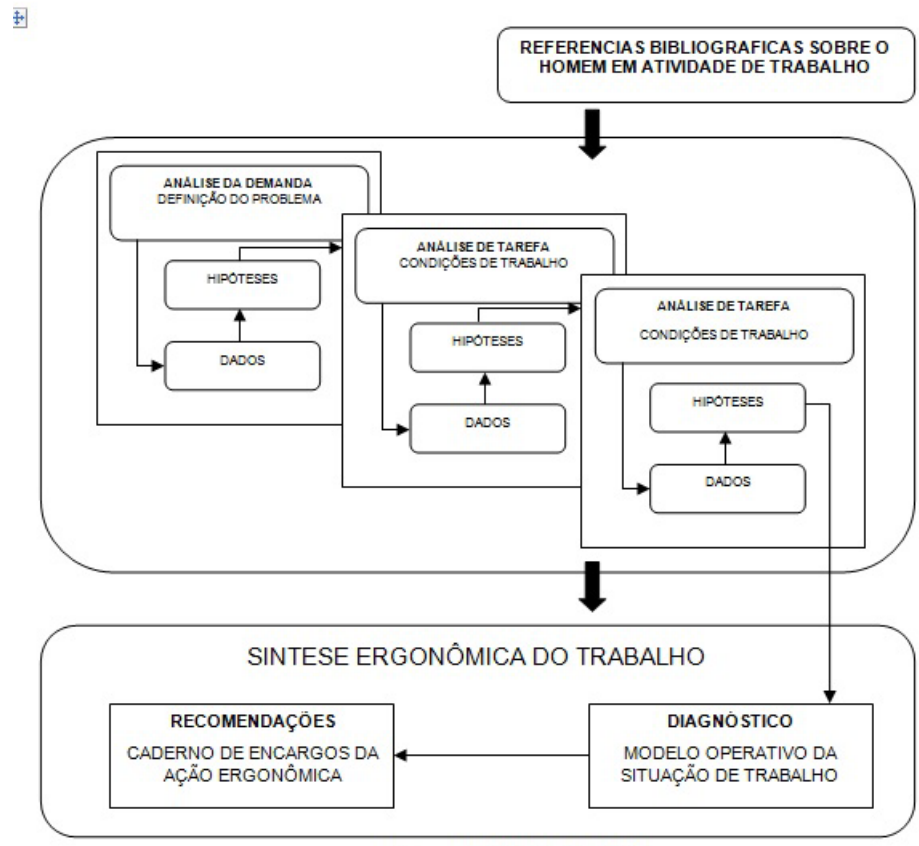

Figura 1. Método da AET

Fonte: Adaptado de Silva (2001) apud Onuka et al (2011) 


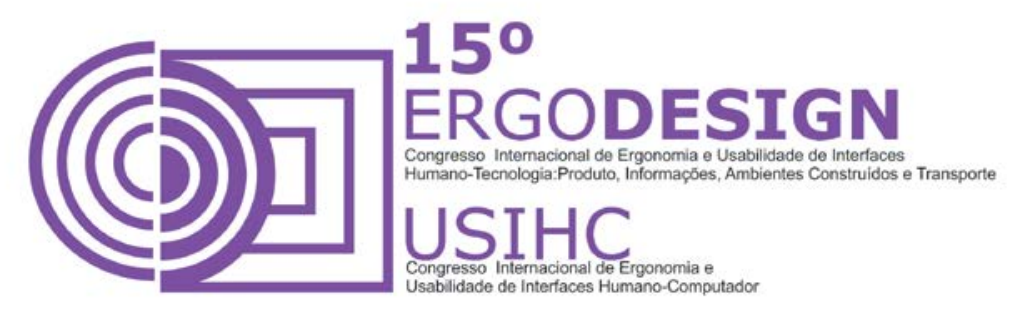

Onde:

- Análise da demanda: parte da identificação da problemática do sistema, seja em nível gerencial, seja por parte dos trabalhadores; também é necessário entender a origem e a dimensão dos problemas identificados;

- Análise da tarefa: nesta fase são identificados os procedimentos executados pelos colaboradores, que devem estar documentados por escrito. Essa análise objetiva descobrir as discrepâncias entre o que é prescrito de maneira formalizada e o que é realmente executado;

- Análise da atividade: aqui são caracterizados os comportamentos dos trabalhadores ao realizar determinada tarefa. Trata-se da forma como os colaboradores trabalham e podem ter influências internas e externas à organização;

- Diagnóstico: neste momento são identificadas as origens e as causas da demanda, que podem significar desde a falta de treinamento até condições insalubres de trabalho;

- Recomendações: o encerro desse programa deve apresentar as providências necessárias para a solução dos problemas diagnosticados, as recomendações devem conter todos os passos da ação ergonômica de forma clara, objetiva e eficiente.

Portanto, o ergonomista não deve ficar passivo perante a demanda que lhe é dirigida, mas deve buscar informações acerca não só dos problemas como também do contexto sociotécnico da empresa junto à direção, aos diversos departamentos que possam estar envolvidos na demanda e aos trabalhadores. Tais dados podem ser obtidos através da realização de entrevistas, da análise de documentos e a partir da utilização de instrumentos complementares, como questionários e checklists (GUÉRIN et al., 2001).

\section{EWA - Ergonomics Workplace Analysis}

Segundo Bormio (2012) "em 1984, o FIOH - Finnish Institute of Occupational Health (Instituto Finlandês de Saúde Ocupacional) de Helsink, tendo a frente Mauno Ahonen, Martti Launis e Tuulikki Kuorinka, criou o a metodologia de Avaliação Ergonômica do Trabalho - EWA.".Shida; Bento (2012) corroboram que "o seu desenvolvimento foi baseado na fisiologia do trabalho, biomecânica ocupacional, aspectos psicológicos, higiene ocupacional e em um modelo participativo da organização do trabalho. Sua aplicação é mais eficaz em trabalhos manuais e atividades que envolvam movimentação manual de materiais."

Shida; Bento (2012) afirmam que para a utilização do EWA é necessária uma descrição detalhada e criteriosa das tarefas e/ou dos postos de trabalho e, para tal, deve-se obter as informações necessárias através da aplicação de questionários (check-list) e a observação sistemática in loco. Os autores ainda articulam que o "EWA é uma ferramenta bem completa, além dos aspectos ambientais e físicos, ela avalia também os aspectos psicossociais e mentais, tais como, a comunicação entre os trabalhadores, atenção ao executar a atividade bem como tomada de decisões.".

Por possuir uma abordagem ampla, que possibilita enfoques subjetivos e objetivos, o método é capaz de desenvolver análises sob diferentes aspectos, que consequentemente resultam em material informativo capaz de transmitir informações a profissionais (projetistas como arquitetos e designers e 
especialistas da saúde) que podem auxiliar e/ou facilitar ações como: a contratação de pessoal, realização de correções checando a qualidade das melhorias feitas, tanto em um posto de trabalho, como nas tarefas, seja de um único posto de trabalho ou fazendo comparação de diferentes postos com o mesmo tipo de atividade e/ou desenvolvimento de novos projetos com configurações seguras, saudáveis e produtivas para os trabalhadores. (BORMIO, 2012)

É recomendada a aplicação do EWA para a realização de análise ergonômica detalhada do local de trabalho, através de itens que enfocam aspectos da fisiologia do trabalho, biomecânica ocupacional, psicológicos e higiene ocupacional, em um modelo participativo com a organização do trabalho (Quadro 1).

Quadro 1. Síntese da Ferramenta EWA

\begin{tabular}{|c|c|c|}
\hline VARIÁVEIS & FATORES DE AVALIAÇÃO & INDICADORES \\
\hline \multirow{10}{*}{ Biomecânicas } & Atividade Física em Geral & - \\
\hline & \multirow{4}{*}{ Levantamento de Cargas } & Altura do levantamento \\
\hline & & Distância das mãos \\
\hline & & Numero de cargas levantadas \\
\hline & & Condições de Levantamento \\
\hline & \multirow{4}{*}{$\begin{array}{l}\text { Postura de Trabalhos e } \\
\text { Movimentos }\end{array}$} & Pescoço - ombros \\
\hline & & Cotovelo - pulso \\
\hline & & Costas \\
\hline & & Quadril Pernas \\
\hline & Repetitividade do trabalho & - \\
\hline \multirow{2}{*}{ Segurança } & \multirow{2}{*}{ Risco de Acidentes } & Intensidade \\
\hline & & Gravidade \\
\hline \multirow{2}{*}{ Psicológicas } & Satisfação com o Trabalho & - \\
\hline & Atenção & - \\
\hline \multirow{3}{*}{ Organizacionais } & Restrições no Trabalho & - \\
\hline & $\begin{array}{lrr}\text { Comunicação } & & \text { entre } \\
\text { Trabalhadores } \\
\text { Pessoais }\end{array}$ & - \\
\hline & Tomada de Decisões & - \\
\hline Mobiliário & Características Físicas & $\begin{array}{l}\text { Área de trabalho horizontal } \\
\text { Altura de trabalho } \\
\text { Visão } \\
\text { Espaço para as pernas } \\
\text { Assento } \\
\text { Ferramentas manuais } \\
\text { Outros equipamentos }\end{array}$ \\
\hline \multirow{2}{*}{ Físico-ambientais } & Iluminação & - \\
\hline & Temperatura & - \\
\hline
\end{tabular}




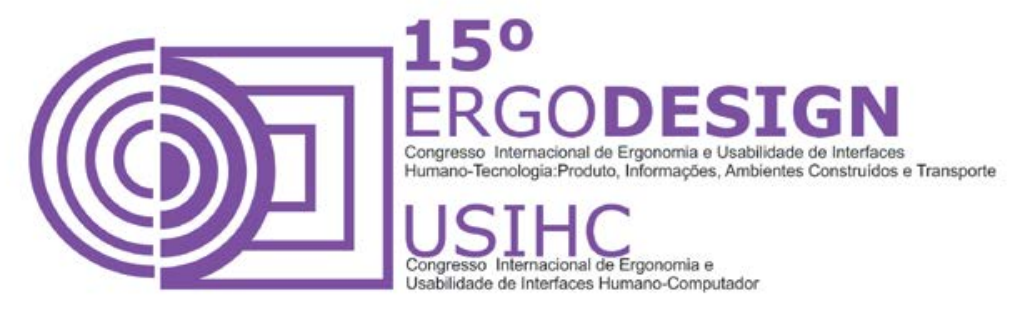

\begin{tabular}{|l|l|l|}
\hline & Ruído & - \\
\hline
\end{tabular}

Fonte: Adaptado de Bormio, 2012

\section{NIOSH - National Institute for Occupational Safety and Health}

Em 1981, o NIOSH - National Institute for Occupational Safety and Health (Instituto Nacional de Saúde e Segurança Ocupacional) publicou um informe técnico intitulado Work Practices Guides for Manual Lifting (Guia de Práticas de Trabalho para Levantamento Manual) (MATEUS JUNIOR, 2009; LIGEIRO, 2010; SHIDA; BENTO, 2012).

O manual tinha como objetivo prevenir ou reduzir a ocorrência de dores causadas por levantamento manual de cargas e para isso foi desenvolvida uma equação para calcular o peso limite recomendável em tarefas repetitivas de levantamento de cargas (IIDA, 2005). Composto por um sumário da literatura sobre o tema, procedimentos analíticos, uma equação para cálculo do peso recomendado para atividades de levantamento com uso das duas mãos e com movimento simétrico e algumas recomendações para controle do risco de lombalgia devido a esse tipo de atividade.

A equação desenvolvida em 1981 pelo NIOSH passou por um processo de revisão em 1985, por um comitê de especialistas, a fim de aprofundar e aperfeiçoar o manual de cargas e, em 1991 e foi sumarizada em um documento intitulado Scientific Support Documantation for the Revised 1991 NIOSH Lifiting Equation (Documentação científica de suporte para a equação NIOSH de levantamento, revisada em 1991, tradução nossa).

Baseado nessa revisão, o comitê recomendou critérios para definição da capacidade de levantamento de trabalhadores saudáveis e os utilizou para formular a equação de levantamento revisada (WATERS; PUTZ-ANDERSON; GARG, 1994) dando origem a uma ferramenta para identificar os riscos de lombalgia, adquirida graças à manipulação de cargas no trabalho, considerando 3 critérios: biomecânico, fisiológico e psicofísico (WATERS et al., 1993; IIDA, 2005).

\section{Recommended Weigth Limit - RWL (LPR - Limite de peso recomendado)}

De acordo com os autores Waters; Putz-Anderson; Garg (1994) RWL é o principal produto da revisão da equação. É definido para alguns conjuntos de condições de atividades, como o peso de um objeto que possivelmente todos trabalhadores saudáveis poderiam trabalhar em um determinado período de tempo, sem aumentar o risco de desenvolver uma lombalgia (Equação 01).

$R W L=L C \times H M \times V M \times D M \times A M \times F M \times C M$

[Eq. 01]

\section{Lifting Index - LI (IL - Índice de levantamento)}

É definido pela relação entre o peso da carga levantada e o limite de peso recomendado (RWL) (WATERS; PUTZ-ANDERSON; GARG, 1994) e é apresentado pela seguinte Equação 2: 


\section{$L I=\frac{\text { peso da carga }(L)}{R W L}$}

[Eq. 02]

Onde: $\mathrm{LI}<1$ tem-se baixo risco; $1<\mathrm{LI}<2$ rico moderado; $\mathrm{LI}>2$ tem-se alto risco.

"Esse índice informa um valor estimado do estresse físico associado com a atividade avaliada" (MATEUS JUNIOR, 2009).

\section{Definições terminológicas}

Para o uso correto da equação é necessário o conhecimento detalhado das terminologias definidas pelos autores da revisão (Quadro 2), (WATERS; PUTZ-ANDERSON; GARG, 1994).

Quadro 2. Definições terminológicas

\begin{tabular}{|l|l|}
\hline Terminologia & Definição \\
\hline Lifting Tasks (Atividades de levantamento) & $\begin{array}{l}\text { Ato de pegar um objeto, com um determinado } \\
\text { tamanho e massa com as duas mãos, e } \\
\text { movimentá-lo verticalmente sem uma ajuda } \\
\text { mecânica. }\end{array}$ \\
\hline Load Weight (L) (Peso da Carga) & $\begin{array}{l}\text { Peso do objeto a ser levantado, em libras ou } \\
\text { quilogramas. }\end{array}$ \\
\hline Horizontal Location (H) (Localização horizontal) & $\begin{array}{l}\text { Distância do ponto médio das mãos ao pegar o } \\
\text { objeto até o ponto médio localizado entre os } \\
\text { tornozelos, em polegadas ou centímetros. }\end{array}$ \\
\hline Vertical Location (V) (Localização vertical) & $\begin{array}{l}\text { Distância das mãos ao pegar o objeto até o chão, } \\
\text { em polegadas ou centímetros (deve ser medida na } \\
\text { origem e no destino do levantamento) }\end{array}$ \\
\hline $\begin{array}{l}\text { Vertical Travel Distance (D) } \\
\text { (Distância percorrida) }\end{array}$ & $\begin{array}{l}\text { Diferença entre as distâncias verticais de origem e } \\
\text { destino, em polegadas ou centímetros. }\end{array}$ \\
\hline Asymmetry Angle (A) (Ângulo assimétrico) & $\begin{array}{l}\text { É o ângulo gerado pela rotação do tronco ao } \\
\text { movimentar a carga. Tendo como referência uma } \\
\text { reta traçada no ponto médio entre os dois } \\
\text { tornozelos, medidos em graus. }\end{array}$ \\
\hline $\begin{array}{l}\text { Lifting Frenquency } \\
\text { levantamento) }\end{array}$ & $\begin{array}{l}\text { Corresponde a posição do corpo quando as mãos } \\
\text { estão diretamente a frente do corpo e existe pouca } \\
\text { rotação de pernas, troncos e membros. }\end{array}$ \\
\hline $\begin{array}{l}\text { Lifting Duration (Frequência de de } \\
\text { levantamento) }\end{array}$ & $\begin{array}{l}\text { Média de levantamentos por minuto, medidos por } \\
\text { um período de 15 minutos. }\end{array}$ \\
\hline trabalho de & $\begin{array}{l}\text { Três classificaçães para a duração do trabalho de } \\
\text { levantamento são especificadas: curta (1h), } \\
\text { moderada (1-2h) e longa (2-8h), dependendo do } \\
\text { padrão de trabalho. }\end{array}$ \\
\hline
\end{tabular}




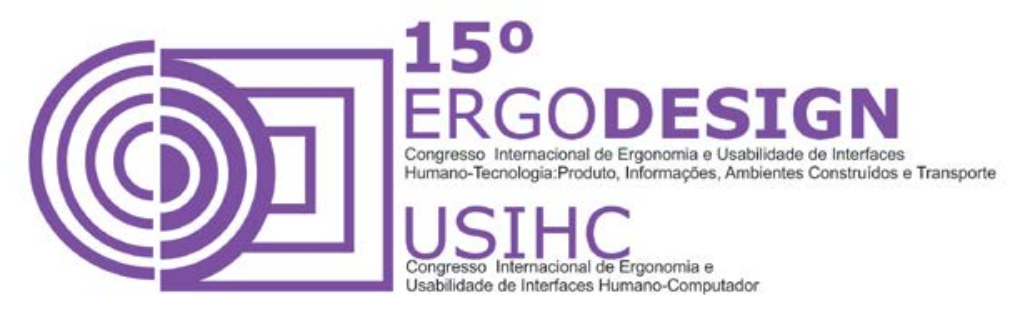

Coupling Classification (Classificação de pega)

Classificação da qualidade da pega mão-objeto, dividida em boa regular e pobre.

\begin{tabular}{l|l} 
Significant Control (Controle Siginificativo) & $\begin{array}{l}\text { Condição que requer do indivíduo um } \\
\text { posicionamento preciso da carga em seu destino. }\end{array}$
\end{tabular}

Fonte: Waters; Putz-Anderson; Garg, 1994.

"A equação revisada de levantamento $\mathrm{NIOSH}$, como dito anteriormente, é uma ferramenta para avaliação do estresse físico das atividades com uso das duas mãos. Como toda ferramenta, sua aplicação é limitada às condições para qual foi projetada" (MATEUS JUNIOR, 2009).

\section{OWAS - Ovako Working Posture Analysing System}

Desenvolvido na Finlândia por Karhu, Kansi e Kuorinka em 1977, Ovako Working Posture Analysing System ou apenas OWAS, é uma ferramenta que tem por objetivo avaliar as posturas assumidas pelos colaboradores por meio da observação do pesquisador (LIGEIRO, 2010).

Segundo lida (2005), a identificação das 72 posturas típicas admitidas pela ferramenta (combinação das 4 posições típicas do dorso, 3 dos braços e 7 das pernas), é definida por 6 dígitos onde 3 descrevem a posição dos seguimentos corpóreos, 1 a carga e 2 o local ou estágio em que a postura foi observada. Em seguida, a identificação da postura é classificada em uma das 4 categorias que apontam diferentes níveis de desconforto e a urgência de uma intervenção:

- Classe 1: postura normal, que dispensa cuidados, a não ser em casos excepcionais;

- Classe 2: postura que deve ser verificada durante a próxima revisão rotineira dos métodos de trabalho;

- Classe 3: postura que deve merecer atenção a curto prazo;

- Classe 4: postura que deve merecer atenção imediata.

Diferentes analistas treinados, observando o mesmo trabalho, fizeram registros com 93\% de concordância, em média (IIDA, ibidem).

No método OWAS, a atividade pode ser subdividida em várias fases e, posteriormente, categorizada para a análise das posturas no trabalho. Na análise das atividades, aquelas que exigem levantamento manual de cargas são identificadas e categorizadas de acordo com o esforço imposto ao trabalhador, embora não seja este o enfoque principal do método. Não são considerados aspectos como vibração e dispêndio energético. Posteriormente, as posturas são analisadas e mapeadas a partir da observação dos registros fotográficos e filmagens do indivíduo em uma situação de trabalho (ZENI, SALLES, BENEDETTI, 2007 apud SHIDA; BENTO, 2012).

O método OWAS é um dos mais simples de observação da análise postural, pois requer pouco tempo para se realizar a observação. Ele provou ser bem funcional na prática de níveis de solo e ser útil nas melhorias do sistema de trabalho e na prevenção de problemas de doenças ocupacionais (KARHU et al, 1981 apud KIVI e MATTILA, 1991). 


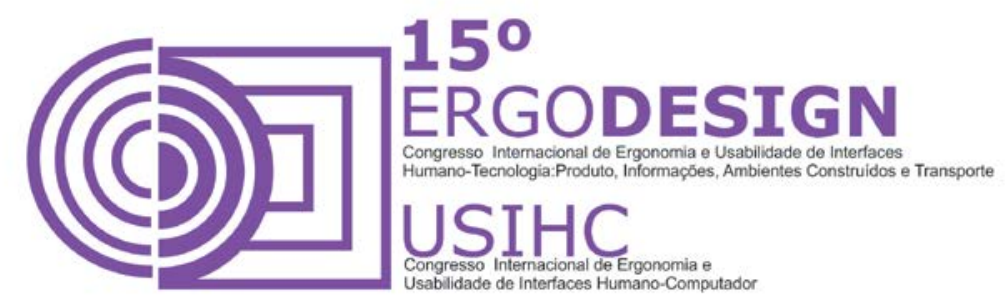

Segundo Ligeiro (2010), a priori é necessário observar o local de trabalho a ser avaliado para identificar as atividades da tarefa e classificá-las como cíclicas ou não cíclicas. Outro elemento importante nesse software é a frequência e o tempo despendido em cada postura, que pode ser verificado coma ajuda de um cronômetro. Em seguida, devem-se registrar as posturas identificando-as pelo código, a partir da seleção da atividade em intervalos constantes ou variáveis. Esta avaliação pode ou não utilizar como auxílio, imagens para registro da tarefa (LIGEIRO, ibidem).

Após a definição da postura no software, representando um código por ele estabelecido, o mesmo classifica-a em quatro categorias ou classes. A percentagem de tempo de duração da postura na jornada de trabalho ou a combinação dos 4 primeiros dígitos do código, determinado pelo software, refere-se às variáveis de posição dos elementos (dorso, braços, pernas e carga) que a postura recebeu, classificando sua categoria. (LIGEIRO, 2010).

Para Shida; Bento (2012) o OWAS "é uma ferramenta ergonômica que se mostrou muito útil na detecção de posturas inadequadas. Sua aplicação aponta possíveis posturas que podem levar o trabalhador ao afastamento devido à lesões por esforços excessivos.". Os autores ainda complementam que sua utilização se restringe às posturas, isto é, apresenta baixa sensibilidade em relação à utilização de cargas, aspectos vibratórios e dispêndio energético. Outra desvantagem do OWAS é que ele não avalia a região cervical, punhos e antebraços e não é possível aplicá-la quando o trabalho é realizado na postura deitada.

\section{RULA - Rapid Upper Limb Assessment}

Rapid Upper Limb Assessment (Avaliação Rápida de Membros Superiores tradução da autora) de onde deriva as siglas RULA, é uma ferramenta de avaliação do risco de DORT e foi desenvolvida em 1993 por McAtamney e Corlett.

Objetivando a classificação integrada de riscos de doenças ocupacionais, particularmente ao posicionamento postural, o método RULA prioriza as intervenções com base numa perspectiva epidemiológica da incidência, por meio das observações realizadas pelo pesquisador sobre 0 ambiente de trabalho (SHIDA; BENTO, 2012).

Utiliza diagramas de posturas do corpo e três tabelas que avaliam o nível de exposição a fatores de risco, que incluem o número de movimentos, a postura estática, a força, a postura de trabalho determinada por equipamentos e mobiliários e tempo de trabalho e pausa, sendo processado em três estágios, a saber: 1. identificação da postura de trabalho; 2. aplicação de sistema de escore e 3 aplicação de escala de níveis de risco.

O RULA é um método observacional de postos de trabalho cujo objetivo é a classificação integrada do risco de Lesões musculoesqueléticas do membro superior ligadas a trabalho LMEMSLT. O objetivo geral é identificar o esforço associado com a postura de trabalho assumida na realização de atividades estáticas ou repetitivas e que podem contribuir para a fadiga muscular e eventual gênese LMEMSLT (SERRANHEIRA; UVA, 2010).

Ligeiro (2010) afirma que sua aplicação resulta em um sistema de códigos, dando origem a uma classificação e uma lista categorizada de ações, indicando o nível de intervenção com o objetivo de reduzir o risco de DORT devido à carga física imposta ao operador. Por meio dos 


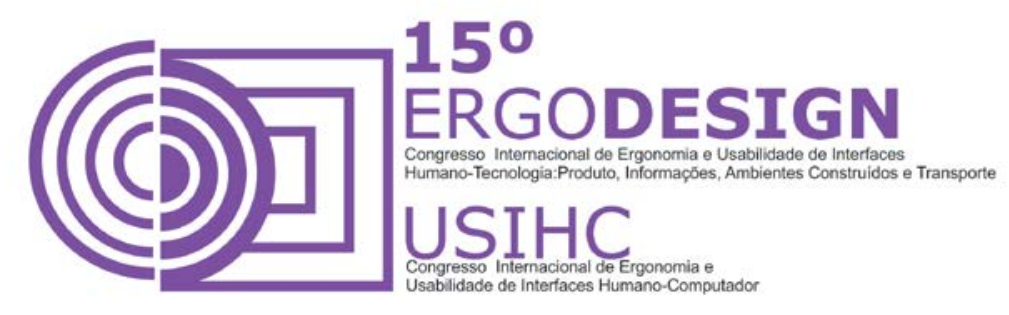

resultados obtidos é possível criar uma tabela ordenada pela pontuação encontrada, relativa à existência de fatores de risco para doenças ocupacionais.

A interpretação dos resultados, segundo a RULA, segue a pontuação da seguinte forma:

- 1 ou 2: aceitável;

- 3 ou 4: investigar;

- 5 ou 6: investigar e mudar logo;

- 7: investigar e mudar imediatamente.

"O RULA é um método rápido de análise postural, estático e dinâmico que foca mais em esforços repetitivos e força, ideal para ser aplicado em funcionários de escritório e atividades que requerem maior esforço de membros superiores" (SHIDA; BENTO, 2012). Porém, apenas é possível avaliar um lado corporal (unilateral - direito ou esquerdo) em cada aplicação do RULA. Se existirem vários fatores de risco relativos à postura assumida ou à atividade exercida, é importante avaliar cada um deles em utilizações singulares do método. Por outras palavras, podem-se executar vários registros em cada posto de trabalho e, consequentemente, obter várias classificações de risco das componentes principais da atividade, em cada posto de trabalho (SERRANHEIRA; UVA, ibidem).

\section{RESULTADOS E CONCLUSÕES}

O ambiente de trabalho, segundo a ergonomia, deve ser adequado às características biomecânicas e psicológicas dos colaboradores, contudo é importante salientar que essas características são particulares e específicas a cada indivíduo, o que corrobora a aplicação das ferramentas de análise ergonômicas de forma pontual.

Através do estudo da revisão bibliográfica pode-se concluir que as ferramentas, métodos e protocolos atuam em pontos específicos e, portanto para que seu emprego seja efetivo, elas não devem ser aplicadas de forma isolada, mas sim conjuntamente a outros métodos como Laudos Ergonômicos e principalmente de maneira multidisciplinar.

Segundo Signori (2000 apud LIGEIRO, 2010), um instrumento confiável e fidedigno, para classificação do risco de desenvolvimento de distúrbios osteomusculares nos ambientes de trabalho, deve verificar todos os fatores (biomecânicos e ambientais) de risco, estabelecer critérios para quantificar a intensidade de cada fator, aplicar-se aos hemicorpos direito e esquerdo separadamente e por fim possibilitar a identificação do risco específico de cada zona corporal (coluna lombar, coluna dorsal, coluna cervical, ombro, cotovelo, punho e mãos).

Este trabalho pode auxiliar profissionais da área de Ergonomia e de áreas correlatas como Engenheiros de Segurança do Trabalho a selecionar as Ferramentas mais adequadas para aplicação e desenvolvimento de ambientes de trabalho. 


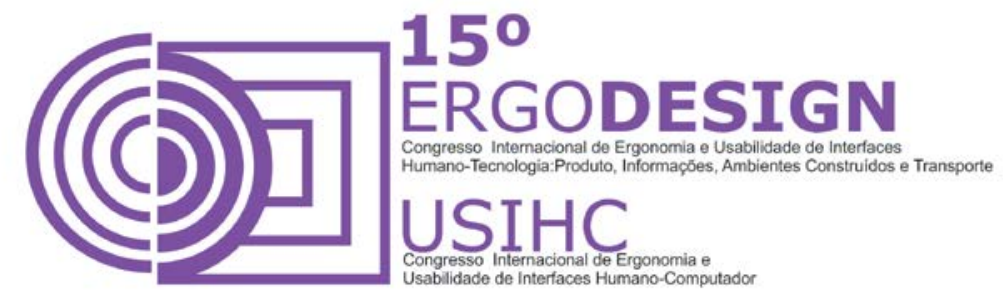

\section{REFERÊNCIAS BIBLIOGRÁFICAS}

ABRAHÃO, J. I.; PINHO D. L. M. Teoria e prática ergonômica: seus limites e possibilidades. In: Escola, Saúde e Trabalho: estudos psicológicos. Maria das Graças T. Paz, Alvaro Tamayo (organizadores) Brasília: Editora Universidade de Brasília, 1999.

BORMIO, Mariana Falcão. Trabalho de teleatendente: proposta de um protocolo de avaliação ergonômica. Tese (Doutorado em Design) Faculdade de Arquitetura, Artes e comunicação - UNESPUniversidade Estadual Paulista, Bauru, 2012.

BRASIL. Ministério do Trabalho e Emprego. Portaria n. 3.214 de 8 de junho de 1978: Normas Regulamentadoras relativas à segurança e medicina do trabalho. NR 17 - Ergonomia. Disponível em: < http://www.mte.gov.br/legislacao/normas_regulamentadoras/nr_17.pdf> Acesso em: dez/2013

CODO, W; GAZZOTTI, A. A. Trabalho e afetividade. In: CODO, W. (Coord.). Educação: carinho e trabalho. Petrópolis: Vozes, 1999, p. 48-59.

GÜÉRIN, F. et al. Compreender o trabalho para transformá-lo: a prática da ergonomia. São Paulo: Edgard Blucher, 2001.

IIDA, I. Ergonomia: projeto e produção. 2a Ed. São Paulo. Edgar Blücher, 2005.

KIVI, P.; MATILLA, M. (1991) Analysis and improvement of work postures in the building industry: aplication on the the computerised OWAS method. Applied Ergonomics, 22 (1), p. $43-48$.

LAVILLE, A. Referências para uma história da ergonomia francófona. In: FALZON, P. (Ed.). Ergonomia. São Paulo: Edgard Blucher, 2007. p. 21-32.

LEPLAT, J.; CUNY, X. Introduction à la psychologie du travail. Paris: PUF, 1977. Engenharia de Produção da Universidade Federal de Santa Catarina.

LIGEIRO, J. Ferramentas de avaliação ergonômica em atividades multifuncionais: a contribuição da ergonomia para o design de ambientes de trabalho. Dissertação (Mestrado) Programa de Pós Graduação em Design. Universidade Estadual Paulista Julio de Mesquita Filho. Bauru - SP. 2010

MATEUS JUNIOR, J. R. Diretrizes para uso das ferramentas de avaliação de carga física de trabalho em ergonomia: equação niosh e protocolo rula. Dissertação (Mestrado) Programa de Pósgraduação em Engenharia de Produção. Universidade Federal de Santa Catarina. Florianópolis. 2009.

MENDES, René. Patologia do trabalho. Rio de Janeiro: Atheneu, 2003.

MONTMOLLIN, M. Vocabulaire de l'Ergonomie. Tolouse. France: Octarès Editions, 2007.

ONUKA, ET AL. Análise ergonômica postural do posto de trabalho do servente na construção civil. In VII Congresso Nacional de Excelência em Gestão. 2011.

SANTOS, N.D.; ET AL. Antropotecnologia: A ergonomia dos Sistemas de Produção. Curitiba: Gênesis, 1997. 


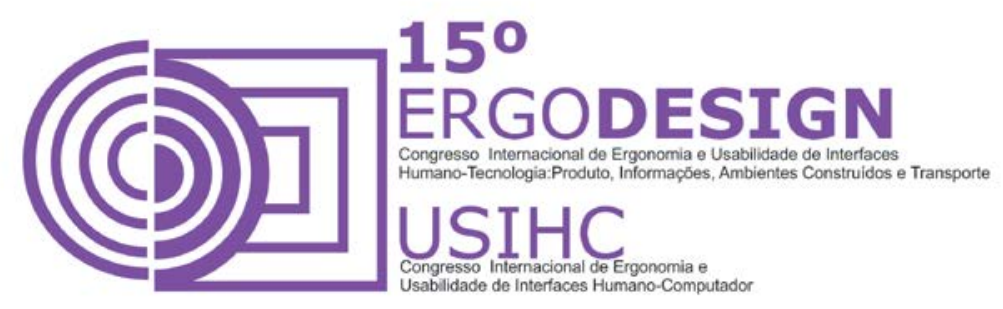

SERRANHEIRA, F.; UVA A. S. LER/DORT: que métodos de avaliação do risco? Artigo In: Revista brasileira. Saúde ocupacional. São Paulo, 35 (122): 314-326, 2010

SHIDA, G. J.; BENTO, P. E. G. Métodos e Ferramentas ergonômicas que auxiliam na análise nas situações de trabalho In VIII Congresso Nacional de Excelência em Gestão. 2012

SILVEIRA, L. D. B. R; SALUSTIANO, E. D. O. A importância da ergonomia no estudo dos tempos e movimentos. Artigo publicado In P\&D em Engenharia de Produção, v. 10, n. 1, p. 71-80. Itajubá. 2012

TOFFLER, Alvin - A Terceira Onda - tradução de: João Távora - 13ª Ed. - Rio de Janeiro: Record, 1980.

WATERS, T. R., PUTZ-ANDERSON, V., GARG, A. Applications Manual for the Revised NIOSH Lifting Equation. DHHS (NIOSH) Publication. No. 94-110. 1994. 